\title{
PRODUTIVIDADE DO AMENDOIM EM FUNÇÃO DA APLICAÇÃO DE DOSES DE GESSO AGRÍCOLA NO INÍCIO DO FLORESCIMENTO
}

\author{
FÁBIO, Leonardo Ângelo ${ }^{1}$ \\ SEGATO, Silvelena Vanzolini ${ }^{2}$
}

Recebido em: 2020.07.31 Aprovado em: 2021.03.29 ISSUE DOI: $10.3738 / 1982.2278 .3825$

\begin{abstract}
RESUMO: O cálcio é um nutriente pouco móvel na planta e que traz benefícios à cultura do amendoim. O gesso é uma fonte de cálcio e enxofre e pode ser usado em cobertura, no início do florescimento, visando promover aporte desse nutriente às plantas de amendoim, que o absorvem também pelas estruturas reprodutivas, notadamente o ginóforo. O presente trabalho teve como objetivo avaliar os componentes de produção e a produtividade do amendoim, em função da aplicação de diferentes doses de gesso agrícola, em área total, em cobertura, no início do florescimento. Foi utilizada a cultivar IAC-OL3, do grupo botânico Virgínia e os tratamentos constaram de quatro doses $\left(0,1000,1500\right.$ e $\left.2000 \mathrm{~kg} \mathrm{ha}^{-1}\right)$ de gesso agrícola, no estádio fenológico R1. O experimento foi conduzido em Sertãozinho, SP e o delineamento experimental utilizado foi em blocos casualizados, com quatro tratamentos e cinco repetições. Cada parcela foi constituída por quatro linhas de $6 \mathrm{~m}$ e espaçamento de 0,90 m. Avaliaram-se componentes de produção e produtividade da cultura do amendoim. Conclui-se que a aplicação de $1000 \mathrm{~kg} \mathrm{ha}^{-1} \mathrm{de}$ gesso agrícola, em cobertura, proporcionou um aumento de número de grãos por vagem, que refletiu em ganho significativo em produtividade.
\end{abstract}

Palavras-Chave: Arachis hypogaea L.,cálcio e enxofre em amendoim, componentes de produção.

\section{PEANUT YIELD AS A RESULT OF THE APPLICATION OF AGRICULTURAL GYPSUM DOSES AT FIRST FLOWERING}

SUMMARY: Calcium is a poorly mobile nutrient in the plant and has benefits for peanut crop. Gypsum is a source of calcium and sulfur and can be used as a cover, at the beginning of flowering, in order to promote the supply of this nutrient to peanut plants, which also absorb it through reproductive structures, notably the gynophores. The present work had as objective to evaluate the components of the production and the productivity of the peanut, in function of the application of different doses of agricultural gypsum in total area, in cover, at first flowering. The cultivar IACOL3, from the Virginia botanical group, was used and the treatments consisted of four doses $(0,1000,1500$ and 2000 $\mathrm{kg} \mathrm{ha}^{-1}$ ) of agricultural plaster, at the phenological stage R1. The experiment was conducted in Sertãozinho, São Paulo State, Brazil. The experimental design used was in randomized blocks, with four treatments and five replicates. Each plot consisted of four $6 \mathrm{~m}$ lines and $0.90 \mathrm{~m}$ spacing. Components of production and productivity of the peanut crop were evaluated. It is concluded that the application of $1000 \mathrm{~kg} \mathrm{ha}^{-1}$ of agricultural plaster, in coverage, provided an increase in the number of grains per pod, which reflected in a significant gain in productivity.

Keywords: Arachis hypogaea L., calcium and sulphur in peanuts, yield components.

\section{INTRODUÇ̃̃̃O}

Em todo o mundo, 44.041.913 toneladas de amendoim são produzidas por ano. A China é o maior produtor de amendoim do mundo, com 16.685.915 toneladas de volume de produção por ano. A Índia vem em segundo lugar, com 6.857 .000 toneladas de produção anual. China e Índia produzem juntas mais de $50 \%$ do total mundial. O Brasil está com 564.785 e está em décimo

1 Engenheiro Agrônomo.

2 Dra. Em Agronomia. Docente Faculdade Dr. Francisco Maeda. Fundação Educacional de Ituverava - FAFRAM/

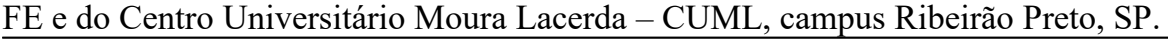

Nucleus, v.18, n.1, abr. 2021 
primeiro. A Nigéria é o terceiro produtor mundial e os EUA o quarto produtor mundial e que possui a maior produtividade (ATLAS BIG, 2021).

A cultura do amendoim é a quarta oleaginosa mais cultivada no mundo, é plantada em larga escala nos continentes americanos, africano e asiático. O plantio é realizado visando a produção de grãos, óleo, farelo entre outros (CONAB, 2017), tendo seus grãos consumidos nos cinco continentes (SEGATO; PENARIOL, 2007).

Segundo dados da safra brasileira de grãos, realizados pela Companhia Nacional de Abastecimento (CONAB, 2020), a produção de amendoim, na safra 2019/2020, distribuída entre primeira e segunda safra, é estimada em 557,3 mil toneladas. A produção é concentrada na primeira safra e foram colhidas 543,6 mil toneladas em uma área de 153 mil hectares, sendo o maior produtor de amendoim no Brasil o Estado de São Paulo (CONAB, 2020). Para a safra atual total de amendoim neste ciclo 2020/21, projeta-se para um aumento de 2,7\% na área em comparação com o ciclo anterior, e uma produção de 575 mil toneladas, 3,1\% maior que a safra passada (CONAB, 2021).

O amendoim gera renda aos produtores, reduz os custos com os tratos culturais da lavoura de cana-de-açúcar em torno de 30\%, além de proporcionar efeitos positivos ao solo, bem como ajudar no controle das pragas que infestam as lavouras (CONAB, 2017).

A planta apresenta raízes que atingem grande profundidade, o que permite a exploração de umidade de camadas do solo normalmente não disponíveis para outras culturas anuais (TASSO JUNIOR; NOGUEIRA; MARQUES, 2004). Esses mesmos autores relataram que déficits de água podem prejudicar a cultura do amendoim através de efeitos indiretos de estresse, como a deficiência de cálcio e fósforo, reduzindo o crescimento, a produção de nódulos radiculares, a fotossíntese e aumentando a respiração das plantas. Crusciol et al. (2000), ao avaliarem a produtividade e os componentes de produção da cultura, notadamente quando a disponibilidade hídrica foi um fator limitante, concluíram que a resposta do amendoim da seca ao cálcio foi baixa em solos com elevado teor de cálcio e de saturação por bases considerada média.

Segundo York Junior e Colwell (1951), uma das funções primárias do cálcio na nutrição do amendoim é auxiliar no maior desenvolvimento dos grãos, mas os resultados positivos são mais evidentes em solos com baixo teor de cálcio.

O cálcio é um nutriente de suma importância na cultura do amendoim, uma vez que a deficiência desse mineral promove a ocorrência de vagens chochas e cascas frágeis, diminuição do índice de fertilidade das flores, redução do número de ginóforos e limitação do crescimento das raízes (WALKER; MULLINIX JUNIOR; KEISLING, 1981). Assim, o cálcio promove casca firme e sadia, diminui vagens sem grãos, melhora a formação dos frutos, promove maior 
fertilidade das flores, aumenta o crescimento das raízes e reduz a ocorrência de doenças causadoras de podridões de raiz (VITTI; FERREIRA; MALAVOLTA, 2008). Esse nutriente é importante para o desenvolvimento do sistema radicular e está diretamente relacionado na quantidade e qualidade dos frutos. Durante a frutificação, as necessidades de cálcio são altas, e este elemento é absorvido pelas raízes, ginóforos e cascas dos frutos em formação (TASSO JUNIOR; NOGUEIRA; MARQUES, 2004).

É grande a necessidade de cálcio na zona de desenvolvimento dos frutos (WALKER, 1975), sendo o terceiro nutriente mais absorvido pela cultura, precedido apenas pelo $\mathrm{N}$ e $\mathrm{K}$ (RODRIGUES FILHO; GODOY; FERTISA, 1986).

Segundo Santos (2005), existem vários insumos que podem ser utilizados como fonte de cálcio, sendo os mais utilizados na cultura do amendoim o calcário e o gesso agrícola.

O gesso agrícola é também fonte de enxofre que é o macronutriente absorvido em menor quantidade pelas plantas de amendoim e faz parte da composição de aminoácidos sulfurados. Sua maior concentração está nos frutos, hastes e folhas, respectivamente. As principais fontes de enxofre são: sulfato de amônia, sulfato de potássio, superfosfato simples e o gesso agrícola (TASSO JUNIOR; NOGUEIRA; MARQUES, 2004).

No amendoim, o gesso se constitui em uma importante fonte de cálcio rapidamente disponível (WALKER, 1975). Quaggio; Dechen e Raij (1982) consideram que a aplicação de gesso aumentou a produção por aumentar a concentração de cálcio na zona de frutificação. $O$ gesso agrícola é também fonte de enxofre e inibidor da atividade do alumínio tóxico em subsuperfície permitindo o maior desenvolvimento radicular, resultando em maior resistência a veranicos e maior aproveitamento dos nutrientes do solo e dos fertilizantes aplicados (VITTI; FERREIRA; MALAVOLTA, 1986). Marques (2008) concluiu que a calagem e a aplicação de gesso superficial incrementam a absorção de macronutrientes, principalmente cálcio e magnésio.

Segundo Bolonhezi; Godoy e Santos (2013), a absorção do íon $\mathrm{Ca}^{++}$depende da concentração no solo e da corrente transpiratória, pois é passivamente absorvido (fluxo de massa) pelo sistema radicular sendo transportado por meio do xilema até a parte aérea. Contudo, como esse íon praticamente não se transloca via floema, não ocorre redistribuição do cálcio para os frutos e sementes, sendo então importante a absorção direta da solução do solo pelos órgãos reprodutivos (ginóforos, cascas e vagens do amendoim). As plantas absorvem a maior parte desse elemento através do ginóforo quando adentra o solo, sendo que nesse ponto ocorre a maior absorção, diretamente da solução do solo (GRICHAR et al., 2012).

A eficiência do gesso é maior quando realizada em cobertura, no início do florescimento, que além de satisfazer com maior frequência as necessidades da planta de amendoim quanto ao cálcio, ficam livres da competição que se estabelece entre cálcio e o 
potássio (WALKER, 1975; QUAGGIO; DECHEN; RAIJ, 1982; SICHMANN; NEPTUNE; MELLO, 1982).

Em vista do exposto, Ferreira et al. (1979), Cox; Adams; Tucker (1982), Quaggio; Dechen; Raij (1982) e Fornasieri et al. (1987) definiram o início do florescimento como sendo a melhor época de aplicação do gesso. Quanto à dose de gesso agrícola a ser utilizada, Vitti; Ferreira; Malavolta (1986) recomendam $500 \mathrm{~kg} \mathrm{ha}^{-1}$ de gesso para solos de textura média e 1000 a $1500 \mathrm{~kg} \mathrm{ha}^{-1}$ para solos argilosos. Contudo, os trabalhos sobre o tema gesso na cultura do amendoim que levaram a essa recomendação são antigos e muitas vezes realizados com cultivar do grupo botânico Valência, que possui extração de nutrientes e de potencial produtivo inferior às cultivares do grupo botânico Virgínia.

Os trabalhos mais recentes sobre o assunto demonstram resultados diversos. Farinelli e Loboda (2005), estudando o efeito da aplicação de gesso agrícola na cultura do amendoim, concluíram que o fornecimento de gesso agrícola em cobertura, no início do florescimento, em área previamente calcariada e com alto teor de cálcio no solo influenciou positivamente no número de vagens por planta, massa de 100 grãos, rendimento e produtividade de vagens do amendoim. Os maiores valores para as características agronômicas foram estabelecidos com aplicação de 200 a $300 \mathrm{~kg} \mathrm{ha}^{-1}$ de gesso em cobertura.

Não houve efeitos significativos da aplicação de gesso agrícola em superfície sobre os componentes de produção do amendoim (FOLONI et al., 2016). Já Spinola e Cicero (2002) observaram interferência positiva da aplicação do gesso agrícola independentemente das doses, na massa média de 100 sementes, germinação e vigor das sementes de amendoim.

A aplicação de gesso influenciou positivamente o número de vagens por plantas e a interação entre gesso e adubação com diferentes doses de potássio demonstrou que valores superiores de produtividade foram obtidos na presença de gesso em cobertura (CAPORUSSO, SILVÉRIO; FARINELLI, 2017).

Ramjeet Yadav et al. (2015) relataram que diferentes parâmetros de crescimento e a produtividade de amendoim aumentaram significativamente com a aplicação de gesso.

A aplicação parcelada de gesso (250 kg na semeadura $+125 \mathrm{~kg}^{-1}$ na floração) aumentou significativamente o número de vagens por planta, o rendimento de vagens e sementes e o índice de colheita de amendoim quando comparado as doses mais baixas e a testemunha sem gesso (JAT; SINGH, 2006).

Betiol, Vitti e Zavaschi (2018) concluíram que a aplicação de gesso em diferentes épocas na cultura do amendoim não teve efeito na produtividade de grãos e vagens, entretanto observou-se que o tratamento com gesso aplicado em pré-plantio incorporado ao solo (500 $\mathrm{Kg}$ ha 
1) e em cobertura no momento do florescimento (500 $\left.\mathrm{Kg} \mathrm{ha}^{-1}\right)$ apresentou maior número de vagens por planta e consequentemente maior número de grãos por planta do que o tratamento com gesso aplicado em pré-plantio $\left(1000 \mathrm{Kg} \mathrm{ha}^{-1}\right)$. Estes autores relatam que o resultado pode ser em função do fornecimento de cálcio na camada de frutificação da cultura no momento do início da emissão dos ginóforos, garantindo adequado desenvolvimento das vagens do solo.

Assim, o objetivo do trabalho foi avaliar os componentes de produção e a produtividade do amendoim, em função da aplicação de diferentes doses de gesso agrícola, em área total, no início do florescimento da cultivar IAC-OL3, do grupo botânico Virgínia.

\section{MATERIAL E MÉTODO}

Local e características do solo. O presente trabalho foi conduzido no ano agrícola de 2015/2016, em Sertãozinho, SP, em talhão de reforma de canavial, em solo de textura muito argilosa (70\% argila, $16 \%$ silte e $14 \%$ de areia total).

Antes da instalação do experimento o solo da área foi amostrado, na profundidade 0,00 0,20 m e 0,20 - 0,40 m, para a caracterização química (Tabela 1). A calagem foi calculada de acordo com o resultado da análise do solo, pelo método de saturação por bases e elevação de Ca e Mg e neutralização do alumínio (QUAGGIO, 1983). De acordo com os cálculos a necessidade de calcário calculada foi de $312 \mathrm{~kg} \mathrm{ha}^{-1}$. Foi utilizado calcário dolomítico com PRNT 90\%.

Tabela 1. Caracterização química do solo amostrado antes da instalação do experimentosobre doses de gesso em início de florescimento, em área de renovação de canavial localizada em Sertãozinho SP, na safra de 2015/2016.

\begin{tabular}{|c|c|c|c|c|c|c|c|c|c|c|c|}
\hline \multirow{2}{*}{$\begin{array}{c}\text { Prof } \\
(\mathrm{m})\end{array}$} & \multirow{2}{*}{$\begin{array}{c}\mathrm{pH} \\
\left(\mathrm{CaCl}_{2}\right)\end{array}$} & \multirow{2}{*}{$\begin{array}{c}\mathrm{MO} \\
\left(\mathrm{g} \cdot \mathrm{dm}^{-3}\right)\end{array}$} & \multirow{2}{*}{$\begin{array}{c}\mathrm{P} \\
\left(\mathrm{mg} \cdot \mathrm{dm}^{-3}\right)\end{array}$} & $\mathrm{K}$ & $\mathrm{Al}$ & $\mathrm{H}+\mathrm{Al}$ & $\mathrm{Ca}$ & $\mathrm{Mg}$ & SB & CTC & \multirow{2}{*}{$\begin{array}{l}\mathrm{V} \\
(\%)\end{array}$} \\
\hline & & & & -... &  & | & tolc. c & & & & \\
\hline $0,00-0,20$ & 5,4 & 30 & 18 & 1,32 & 0 & 25 & 23 & 7 & 31,32 & 56,32 & 55 \\
\hline $0,20-0,40$ & 5 & 25 & 26 & 0,49 & 0 & 31 & 12 & 3 & 15,49 & 46,49 & 33 \\
\hline
\end{tabular}

Fonte: Elaborado pelos autores (2020)

De acordo com a interpretação dos teores de cada nutriente, na camada de $0,00-0,20 \mathrm{~m}$ (camada arável), proposto por Raij et al. (1996) foi observado que o pH, P, Mg e V\% médios, K baixo, Ca alto. No entanto, não foi utilizado nenhum adubo no plantio.

Cultivar. Foi utilizada a cultivar de amendoim (Arachis hypogaea L.) IAC-OL3, peneira circular 19, ou seja, 19/64” de polegadas (7,541 mm) Mooca (grãos ovóides), sementes adquiridas na cooperativa Copercana (Cooperativa dos Plantadores de Cana-de-açúcar do Oeste do Estado de São Paulo), em Sertãozinho, SP, já tratadas com fungicidas carboxina e tiram, 
inseticida tiametoxam e polímero RedSeed $\AA$, nas doses de 250, 200 e $200 \mathrm{~mL}$ do produto comercial por $100 \mathrm{Kg}$ de sementes, respectivamente.

Tal cultivar foi obtida da geração $\mathrm{F}_{6}$ do cruzamento entre o IAC 886-46 (linha selecionada da população original do IAC 886) e amostras do germoplasma acesso $\mathrm{n}^{\circ} 2562$ (GOODY et al., 2014). Essa cultivar é do grupo botânico Virgínia que possui ciclo entre 125 e 130 dias, sendo muito utilizada em áreas de renovação de canavial. As vagens, em sua maioria, com dois grãos, tegumento claro de tonalidade rosada, "alto oleico" com teores entre $70 \%$ a $80 \%$ de ácido oléico no óleo; com predominância das peneiras 19 e 21 . Têm produtividade média de $4.500 \mathrm{~kg} \mathrm{ha}^{-1}$ com potencial de $7.000 \mathrm{~kg} \mathrm{ha}^{-1}$, suscetível à pinta preta (Cercosporidium personatum), mancha castanha (Cercospora arachidicola) e ferrugem (Puccinia arachidis), sendo necessário de 6 a 8 pulverizações com fungicidas recomendados (IAC, 2017).

Delineamento experimental e tratamentos. O delineamento experimental utilizado foi em blocos casualizados com quatro tratamentos (doses de gesso) e cinco repetições. Cada parcela composta de quatro linhas espaçadas 0,90 metro com 6 metros de comprimento obtendo então, uma dimensão de 3,6 m x $6 \mathrm{~m}$, resultando em uma área de $21,6 \mathrm{~m}^{2}$ por parcela, sendo 2 metros a distância entre elas. Foi considerada área útil as duas linhas centrais desconsiderando 1 metro de cada extremidade, obtendo uma área útil de $7,2 \mathrm{~m}^{2}$.

Os quatro tratamentos foram: Testemunha (sem a aplicação de gesso agrícola) e aplicação de diferentes doses de gesso agrícola, em área total, em início do florescimento (1000 $\mathrm{kg} \mathrm{ha}^{-1} ; 1500 \mathrm{~kg} \mathrm{ha}^{-1}$ e $\left.2000 \mathrm{~kg} \mathrm{ha}^{-1}\right)$.

Implantação, condução e avaliações. O preparo de solo foi feito com gradagem pesada, seguida de subsolagem, gradagem intermediária e niveladora.

A semeadura foi realizada dia 25/10/2015 com uma semeadora a vácuo com acoplamento de três pontos da marca Tatu modelo PHT3, regulada para a aplicação de 25 sementes por metro.

Foi observada a emergência das plantas oito dias após a semeadura e aos dez dias após a semeadura foi o momento em que se realizou a marcação das parcelas e a contagem das plantas, avaliando-se o número de plantas por metro linear.

O gesso agrícola foi adquirido na Cooperativa Copercana, em Sertãozinho, SP. Foi coletada uma amostra mantida em saco plástico fechado (para evitar a perda de umidade) e levada ao Campus do Centro Universitário Moura Lacerda, Ribeirão Preto, SP, para análise da umidade do gesso que seria usado (realizada em estufa).

Para a determinação da umidade foram separadas três amostras e colocadas cada uma em um recipiente metálico com identificação e pesado o conjunto recipiente + gesso agrícola para 
a determinação do peso úmido. Os recipientes contendo gesso agrícola foram levados para uma estufa com circulação de ar a $105{ }^{\circ} \mathrm{C}$ por sete dias. No sétimo dia os recipientes com o gesso agrícola foram pesados para a determinação do peso seco e a umidade foi calculada utilizando a seguinte equação: $\mathrm{H}=((\mathrm{PU} 1+\mathrm{PU} 2+\mathrm{PU} 3) /(\mathrm{PS} 1+\mathrm{PS} 2+\mathrm{PS} 3))-1$

Em que: $\mathrm{H}$ = grau de umidade \% (em decimal); PU1; PU2; PU3 = Peso úmido do conjunto recipiente + gesso agrícola das amostras 1, 2 e 3; PS1; PS2; PS3 = Peso seco do conjunto recipiente + gesso agrícola das amostras 1,2 e 3.

Considerou-se $21 \%$ de umidade, com isso, foi realizado cálculos de quantidade de gesso a ser aplicado em cada parcela e corrigindo para uma umidade de 17\% (umidade livre), ou seja, em cada parcela que recebeu o gesso, foram aplicados $4 \%$ a mais de gesso.

A aplicação do gesso agrícola foi feita manualmente em área total no dia 03/12/2015 (39 dias após a semeadura) quando as plantas estavam iniciando o florescimento, estádio fenológico R1 (BOOTE, 1982).

As aplicações de defensivos foram as mesmas em todos os tratamentos e feitas pelo produtor com um pulverizador com acoplamento de três pontos com capacidade para 600 litros de calda. Os fungicidas utilizados foram: Clorotalonil; Piraclostrobina + Epoxiconazol; Difeconazol. Os inseticidas utilizados foram: Diflubenzurom; Alfa-cipermitrina; Tiametoxam + Lambda-cialotrina. O acaricida utilizado foi o Propargito.

Os dados de precipitação e temperatura média foram coletados no site IPMET (IPMET, 2017). O mês de janeiro de 2016 foi o que teve maior precipitação acumulada com 380,2 mm e o mês de fevereiro com maior temperatura média $27,5^{\circ} \mathrm{C}$.

Figura 1. Precipitação mensal acumulada em $\mathrm{mm}$ e temperatura média em ${ }^{\circ} \mathrm{C}$ no município de Sertãozinho/SP durante o experimento sobre doses de gesso em início de florescimento. Safra 2015/2016. Sertãozinho, SP.

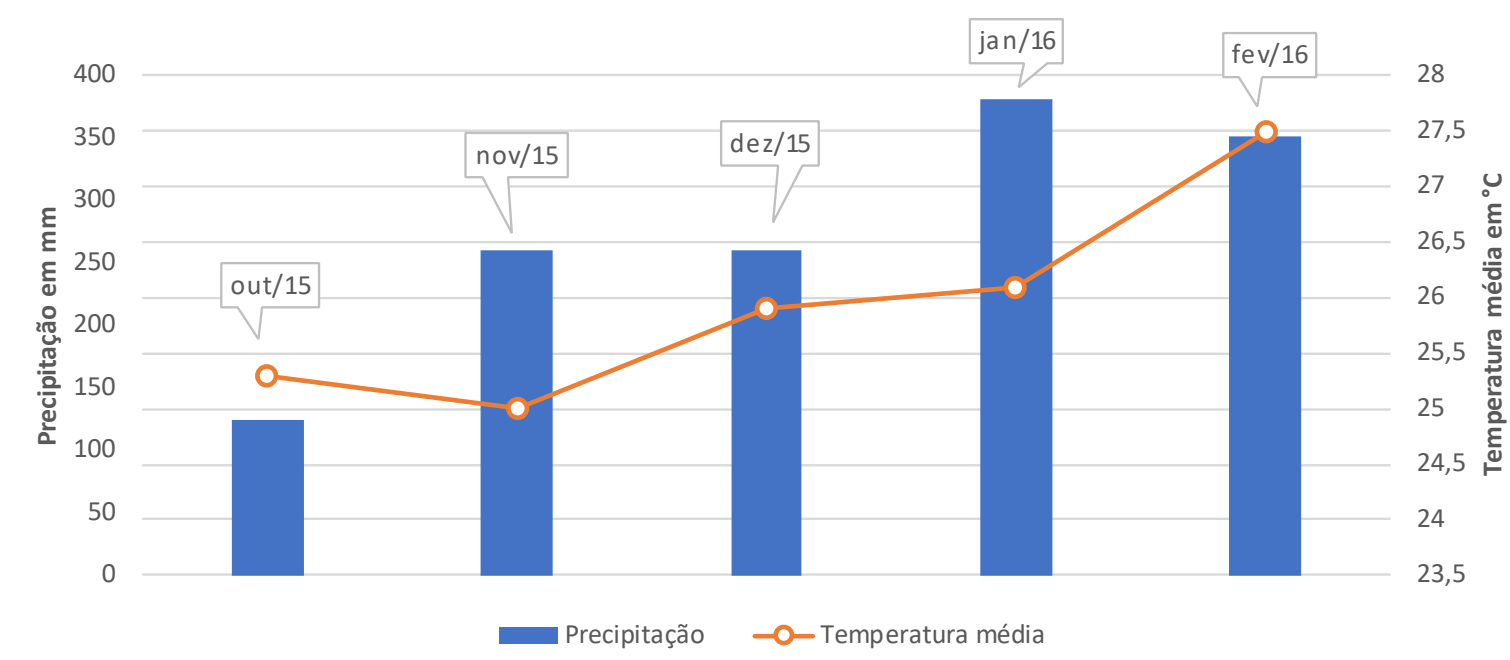

Fonte: Ipmet (2017). 
Os dados demonstram que tanto a temperatura média, quanto a precipitação pluviométrica ocorrida nos meses de condução do experimento (Figura 1) foi adequada a boa produção da cultura, ressaltando somente o grande volume de chuva no mês da colheita.

Foi utilizado o método "Hull Scrape" (WILLIAMS; DREXLER, 1981) para determinar a maturação do amendoim, que consiste na raspagem da parte exterior das vagens, expondo a coloração do mesocarpo. Para isso foi arrancada uma planta por parcela da área não útil, coletado as vagens totalmente desenvolvidas e posteriormente foram raspadas com um canivete. $\mathrm{O}$ ponto de maturação foi constatado quando ao menos $70 \%$ das vagens apresentavam o mesocarpo na coloração preta, marrom ou laranja. O arranquio das parcelas foi realizado no dia 27/02/2016 (122 dias após a semeadura).

Para facilitar o arranquio manual, foi utilizado um implemento acoplado em um trator que possuía duas enxadas que passavam a uma profundidade de $12 \mathrm{~cm}$ da superfície do solo e afofava a terra. Foi considerada área útil da parcela as duas linhas centrais, desconsiderando 1 metro de cada linha nas bordaduras, perfazendo $7 \mathrm{~m}^{2}$.

Para saber o ponto certo de colheita foram coletadas amostras de grãos (colocadas em sacos de plástico) aos quatro e cinco dias após o arranquio e levados à cooperativa Copercana para fazer o teste de umidade. Aos quatro dias a umidade estava 10,3\% e aos cinco dias 9,2\%. Assim, a coleta das vagens de cada parcela na área útil foi feita manualmente aos cinco dias após o arranquio.

Inicialmente foram coletadas as vagens de 10 plantas em cada parcela útil para determinar os componentes de produção: número de grãos por vagem, massa de vagens, massa de casca e massa de grãos.

Para avaliar a produtividade, o total de vagens colhidas em cada parcela, na área útil, foi pesada (somando-se as 10 plantas anteriormente coletadas) e o valor extrapolado para produção em um hectare (produtividade).

Os dados coletados foram submetidos à análise de variância, e a comparação entre médias foi realizada pelo teste de Tukey a 5\% de probabilidade. As análises estatísticas foram feitas utilizando o programa ASSISTAT (SILVA; AZEVEDO, 2016).

\section{RESULTADO E DISCUSSÃO}

Em cultivares rasteiras, o espaçamento entrelinhas deve ser de $90 \mathrm{~cm}$ com cerca de 12 a 14 plantas por metro (GODOY et al., 2014) e pelos dados contidos na Tabela 2, verifica-se que a 
densidade de semeadura foi homogênea para todos os tratamentos ficando em aproximadamente 14 plantas por metro linear, tal fato é importante, pois demonstra que a densidade de plantas foi adequada e esse fator não interferiu nos dados do experimento.

Tabela 2. Número de plantas de amendoim, IAC - OL3, emersas por metro e porcentagem de emergência em campo (EC\%). Contagem feita 10 dias após a semeadura em experimento sobre doses de gesso em início de florescimento. Ano agrícola de 2015/2016. Sertãozinho, SP.

\begin{tabular}{lll}
\hline Tratamentos $\left(\mathbf{k g ~ h a}^{-\mathbf{1}}\right)$ & Plantas emersas por metro & EC (\%) \\
\hline Testemunha & $14,04 \mathrm{a}$ & 56,16 \\
1000 & $13,87 \mathrm{a}$ & 55,48 \\
1500 & $14,27 \mathrm{a}$ & 57,08 \\
2000 & $13,82 \mathrm{a}$ & 55,28 \\
\hline CV\% & 5,13 & - \\
DMS & 1,34 & - \\
\hline
\end{tabular}

*Médias seguidas pela mesma letra, na coluna, não diferem entre si pelo teste de Tukey a $5 \%$ de probabilidade. $\mathrm{CV}$ : coeficiente de variação. DMS: diferença mínima significativa.

Fonte: Elaborado pelos autores (2020)

Verificou-se também que a porcentagem de emergência de plantas em campo (Tabela 2) situou-se em aproximadamente 55\% demonstrando um problema recorrente em sementes de amendoim que é a baixa germinação e emergência de plântulas em campo, fazendo com que o produtor use alta densidade de sementes por metro linear para atingir estande adequado.

$\mathrm{Na}$ Tabela 3 encontram-se os dados dos componentes de produção na cultura do amendoim.

Tabela 3. Dados médios de componentes de produção da cultura do amendoim em experimento sobre doses de gesso em início de florescimento. Ano agrícola de 2015/2016. Sertãozinho, SP, 2020.

\begin{tabular}{llllll}
\hline Doses de gesso & \multicolumn{1}{c}{ Vagens } & $\begin{array}{c}\text { Grãos por } \\
\text { vagem }\end{array}$ & $\begin{array}{c}\text { Vagens com } \\
\text { um grão }\end{array}$ & $\begin{array}{c}\text { Vagens com } \\
\text { dois grãos }\end{array}$ & $\begin{array}{c}\text { Vagens com } \\
\text { três grãos }\end{array}$ \\
\hline kg ha $^{-1}$ & & \multicolumn{5}{c}{ Número } \\
\hline 0 & $178,6 \mathrm{a}^{*}$ & $1,77 \mathrm{~b}$ & $41,8 \mathrm{a}$ & $135,6 \mathrm{a}$ & $1,2 \mathrm{a}$ \\
1000 & $194,8 \mathrm{a}$ & $1,86 \mathrm{a}$ & $29,2 \mathrm{a}$ & $162,4 \mathrm{a}$ & $3,2 \mathrm{a}$ \\
1500 & $180,4 \mathrm{a}$ & $1,82 \mathrm{ab}$ & $33,6 \mathrm{a}$ & $144,6 \mathrm{a}$ & $2,2 \mathrm{a}$ \\
2000 & $171,0 \mathrm{a}$ & $1,80 \mathrm{ab}$ & $35,8 \mathrm{a}$ & $133,4 \mathrm{a}$ & $1,8 \mathrm{a}$ \\
\hline $\mathrm{CV}(\%)$ & 18,64 & 2,39 & 23,05 & 18,84 & 54,81 \\
$\mathrm{DMS}$ & 63,46 & 0,08 & 36,26 & 50,95 & 2,08 \\
\hline
\end{tabular}

*As médias seguidas de mesma letra na coluna, não diferem significativamente entre si pelo teste de Tukey a $5 \%$. CV: coeficiente de variação. DMS: diferença mínima significativa.

Fonte: Elaborado pelos autores (2020)

Apenas o número de grãos por vagem demonstrou diferença significativa de resultado entre os tratamentos (Tabela 3), evidenciando que o tratamento de $1000 \mathrm{~kg} \mathrm{ha}^{-1}$ de gesso agrícola foi a dose que proporcionou melhor resultado e diferiu estatisticamente da testemunha (sem 
gesso). Jat e Singh (2006) e Betiol; Vitti e Zavaschi (2018) também encontraram efeito positivo para esse componente de produção quando o gesso foi aplicado em cobertura.

Jat e Singh (2006); Caporusso, Silverio e Farinelli (2017) e Betiol, Vitti e Zavaschi (2018) verificaram que a aplicação de gesso em cobertura na cultura do amendoim, no início do florescimento, aumentou o número de vagens por planta. Enquanto no presente trabalho (Tabela 3) apenas uma tendência do uso de gesso agrícola na dose de $1000 \mathrm{Kg} \mathrm{ha}^{-1}$ promover maior número de vagens por planta, sem, contudo, apresentar diferença estatística significativa entre os tratamentos. Os dados obtidos também não corroboram os dados de Farinelli e Loboda (2005), que assim como no presente experimento, conduziu a pesquisa em área previamente calcariada e com alto teor de cálcio no solo concluindo que o fornecimento de gesso agrícola em cobertura influenciou positivamente no número de vagens planta $^{-1}$. Porém, assim como no presente trabalho, Foloni et al. (2016) não encontraram efeitos significativos da aplicação de gesso agrícola em superfície sobre esse componente de produção.

Não houve efeito significativo para os demais componentes de produção do amendoim avaliados (Tabela 3), mas há uma tendência que a dose de $1000 \mathrm{~kg}^{-1} \mathrm{~h}^{-1}$ reduziu o número de vagens com um grão e aumentou o número delas com dois e três grãos, segundo IAC (2017) essa cultivar possui vagens, em sua maioria, com dois grãos o que pode sugerir que o gesso colocado no início do florescimento, em cobertura, forneceu cálcio pela absorção das estruturas de reprodução do amendoim (QUAGGIO; DECHEN; RAIJ, 1982; TASSO JUNIOR; NOGUEIRA; MARQUES, 2004; MARQUES, 2008; GRICHAR et al., 2012; BOLONHEZI; GODOY; SANTOS, 2013) levando a cultura a se beneficiar dessa condição amplamente relatada na literatura (WALKER; MULLINIX JUNIOR; KEISLING, 1981; VITTI; FERREIRA; MALAVOLTA, 1986; VITTI et al., 2008), que culminou com o aumento significativo do número de grãos por vagens verificados (Tabela 3 ).

Os dados de massa das vagens e da casca (Tabela 4) não demonstraram diferenças entre os tratamentos avaliados. Observando esses dados é possível verificar que a porcentagem de casca variou de $26,4 \%$ na testemunha a $22,9 \%$ na dose de $1000 \mathrm{Kg} \mathrm{ha}^{-1}$ de gesso agrícola, tendo valores intermediários para as demais doses, o que pode denotar uma tendência de que a massa dos grãos foi menor no tratamento sem gesso.

A produtividade resultante da aplicação de $1000 \mathrm{Kg} \mathrm{ha}^{-1}$ de gesso agrícola diferiu significativamente da produtividade da testemunha em mais de $750 \mathrm{Kg} \mathrm{ha}^{-1}$ (30 sacas ha ${ }^{-1}$, ou seja, mais de 13\%. Também Quaggio; Dechen e Raij (1982); Farinelli e Loboda (2005); Jat e Singh (2006); Caporusso; Silverio e Farinelli (2017) relataram aumento de produtividade com uso de gesso agrícola na cultura do amendoim, em cobertura, no florescimento. 
Tabela 4. Dados médios de componentes de produção da cultura do amendoim e produtividade em experimento sobre doses de gesso em início de florescimento. Ano agrícola de 2015/2016. Sertãozinho, SP. 2020.

\begin{tabular}{llll}
\hline $\begin{array}{c}\text { Doses de gesso } \\
\left(\mathbf{k g ~ h a}^{-1}\right)\end{array}$ & \multicolumn{1}{c}{$\begin{array}{c}\text { Massa de vagens } \\
(\mathbf{g})\end{array}$} & $\begin{array}{c}\text { Massa de casca } \\
(\mathbf{g})\end{array}$ & $\begin{array}{c}\text { Produtividade } \\
\left(\mathbf{k g ~ h a}^{-1}\right)\end{array}$ \\
\hline 0 & $188,4 \mathrm{a}^{*}$ & $49,8 \mathrm{a}$ & $4971,85 \mathrm{~b}$ \\
1000 & $215,8 \mathrm{a}$ & $49,4 \mathrm{a}$ & $5726,66 \mathrm{a}$ \\
1500 & $211,6 \mathrm{a}$ & $51,6 \mathrm{a}$ & $5323,70 \mathrm{ab}$ \\
2000 & $205,6 \mathrm{a}$ & $49,0 \mathrm{a}$ & $5181,48 \mathrm{ab}$ \\
\hline CV $(\%)$ & 11,57 & 15,72 & 7,09 \\
DMS & 44,62 & 14,74 & 704,73 \\
\hline
\end{tabular}

*As médias seguidas de mesma letra na coluna, não diferem significativamente entre si pelo teste de Tukey a $5 \%$. CV: coeficiente de variação. DMS: diferença mínima significativa.

Fonte: Elaborado pelos autores (2020)

Os dados encontrados corroboram a recomendação de Vitti; Ferreira; Malavolta (1986) que para solos de textura argilosa a dose de gesso deve ser de 1000 a $1500 \mathrm{~kg} \mathrm{ha}^{-1}$. No presente experimento as condições de clima adequado e os teores de nutrientes do solo demonstram que a dose $1000 \mathrm{~kg} \mathrm{ha}^{-1}$ seria a recomendada para a melhor produtividade. As doses mais elevadas também elevaram a produtividade da cultura, mas não diferiram estatisticamente da testemunha e não devem ser recomendadas, pois não resultaram em maior produtividade do que a dose $1000 \mathrm{~kg}$ $\mathrm{ha}^{-1}$ e é possível que possam induzir desequilíbrio nutricional.

\section{CONCLUSÃO}

Em solo de textura muito argilosa e com alto teor de cálcio, a aplicação de gesso agrícola, em área total, no início do florescimento, na dose de $1000 \mathrm{~kg} \mathrm{ha}^{-1}$ proporcionou aumento significativono número de grãos por vagens e na produtividade na cultura de amendoim.

\section{REFERÊNCIAS}

ATLAS BIG. Principais produtores de amendoim. Disponível em: https://www.atlasbig.com/pt-br/paises-por-producao-de-amendoim\#: :text=Lista $\% 20 \mathrm{de} \% 20$ pa $\% \mathrm{C} 3 \% \mathrm{ADses} \% 20$ por $\% 20$ produ $\% \mathrm{C} 3 \% \mathrm{~A} 7 \% \mathrm{C} 3 \% \mathrm{~A} 3 \mathrm{o} \% 20 \mathrm{de} \% 20$ amendoim\&text $=\mathrm{A} \% 20 \mathrm{China}$ \%20\%C3\%A9\%200\%20maior, 564.785\%20e\%20est\%C3\%A1\%20. Acesso em: 28 mar. 2021.

BETIOL, R.A.B.; VITTI, G.C.V.; ZAVASCHI, E. Épocas de aplicação de gesso agrícola na cultura do amendoim (Arachis hypogaea L.). Encontro Sobre a Cultura do Amendoim, 15. Jaboticabal: FCAV/UNESP. 2018. Disponível em: https://proceedings.science/encontroamendoim-2018/papers/epocas-de-aplicacao-de-gesso-agricola-na-cultura-do-amendoim(arachis-hypogaea-1.). Acesso em: 02 jul. de 2020.

BOLONHEZI, D.; GODOY, I. J.; SANTOS, R. C. Manejo cultural do amendoim. In: SANTOS, R. C. (Ed.). O Agronegócio do amendoim no Brasil. 2. Ed. Campina Grande: Embrapa Algodão, 2013. p.185-238. 
BOOTE, K. J. Growth Stages of Peanut (Arachishypogaea L.). Peanut Science, v.9, n.1, p.3540.1982 .

CAPORUSSO, V.G.; SILVERIO, G.G; FARINELLI, R.Resposta do amendoim submetido à gessagem e adubação potássica. Encontro Sobre a Cultura do Amendoim, 14. Jaboticabal: FCAV/UNESP. 2017. Disponível em:

https://proceedings.science/encontro-amendoim-2017/papers/resposta-do-amendoim-submetidoa-gessagem-e-adubacao-potassica. Acesso em: 02 jul. de 2020.

CONAB. Acompanhamento da safra brasileira de grãos v. 4 - safra 2016/17, n8 - oitavo levantamento, maio 2017. Disponível em: $<$ http://www.agricultura.gov.br/noticias/conab-prevesupersafra-de-232-milhoes-de-toneladas-de-graos/boletim-graos-maio-2017.pdf $>$. Acessoem: 1 nov. 2017.

CONAB - Companhia Nacional de Abastecimento. Acompanhamento da safra brasileira: grãos, v. 7 - Safra 2019/20 - Oitavo levantamento, Brasília, p. 1-66, maio 2020. Disponível em: $<$ https://www.conab.gov.br/info-agro/safras $>$. Acesso em: 26 mai. 2020.

CONAB - COMPANHIA NACIONAL DE ABASTECIMENTO. Acompanhamento da Safra Brasileira de Grãos, Brasília, DF, v. 8, safra 2020/21, n. 6, sexto levantamento, mar. 2021. Disponível em: www.conab.gov.br. Acesso em: 28 mar. 2021.

COX, F.R.; ADAMS, F.; TUCKER, B.B. Liming, fertilization and mineral nutrition. In: PATTEE, H. E.; YOUNG, C.T. (eds.). Peanut science and technology. Yoakum: American Peanut Research and Education Society, 1982. p.139-163

CRUSCIOL, C. A; LAZARNI, E.; GOLFETO, A. R.; SÁ, M. E. de. Produtividade e componentes de produção do amendoim da seca em razão da época de semeadura e da aplicação de Ca. Pesquisa agropecuária brasileira, Brasília, v.35, n.8, p.1549-1558, ago. 2000.

FARINELLI, R.; LOBODA, M.S. Efeito da aplicação de gesso agrícola no comportamento da cultura do amendoim. Cultura Agronômica, Ilha Solteira, v.15, n.2, p.1-20, 2005.

FERREIRA, M.E.; FORNASIERI, D.; VITTI, G.C.; MARVULO, C. Estudo de doses e época de aplicação do gesso na cultura do amendoim (Arachis hypogaea L.). Científica, Jaboticabal, v.7, n.2, p.235-240, 1979.

FOLONI, J. S. S. et al. Efeitos da gessagem e da adubação boratada sobre os componentes de produção da cultura do amendoim.Sci. Agrar. Paraná, Marechal Cândido Rondon, v. 15, n. 2, abr./jun., p. 202-208, 2016.

FORNASIERI, J.L.; FERREIRA, M.E.; VITTI, G.C.; FORNASIERI-FILHO, D. Efeitos do uso de calcário e de gesso sobre algumas características produtivas do amendoim (Arachis hypogaea L.) das águas. Científica, Jaboticabal, v.15, n.1/2, p.45-54, 1987.

GRICHAR, W.J.; NESTER, P.R.; E D COLBUR, A. Nutsedge (Cyperus spp.) Control in Peanuts (Arachis hypogaea) with Imazethapyr.Weed Technology.v.6, n. 2, p. 394-400, 2012.

GODOY, I. J. et al. Amendoim. AGUIAR, A.T.E. et al. (Eds.). Instruções agrícolas para as

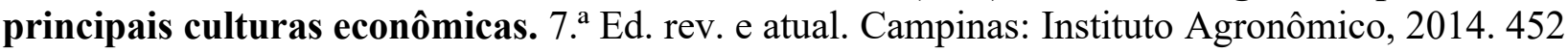
p. (Boletim IAC, n. ${ }^{\circ}$ 200). p.22-27. 
GOODY, I.J. et al.. IAC OL 3 and IAC OL 4: new Brazilian peanut cultivars with the high oleic trait. Crop Breeding and Applied Biotechnology, v.14, p. 200-203, 2014.

IAC. Cultivares-Amendoim. Disponível em:

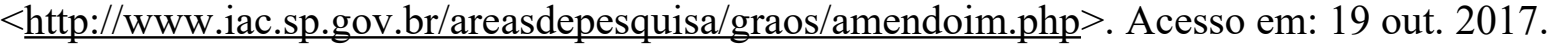

IPMET.Dados meteorolológicos mensais. Disponível em:

$<$ https://www.ipmet.unesp.br/index2.php?menu_esq1=\&abre=ipmet_html/estacao/ historico.php>. Acesso em: 12 nov. 2017.

JAT,R. L.; SINGH, P.. Effect of Gypsum and Plant Growth Regulators on Yield Attributes and Yields of Groundnut (Arachis hypogaea L.). J. Agric. Sci. V.2, n.1, p.228- 230, 2006.

MARQUES, R. R. Aplicação superficial de calcário e gesso em manejo conservacionista de solo para cultivo de amendoim e aveia branca. 2008. 142 f. Dissertação (Doutorado em agronomia) - Faculdade de Ciências Agronômicas da UNESP - Campus de Botucatu, São Paulo, 2008.

QUAGGIO, J.A.; DECHEN, A.R.; RAIJ, B.van. Efeitos da aplicação de calcário e gesso sobre a produção de amendoim e lixiviação de bases no solo. Revista Brasileira de Ciência do Solo, Campinas, v.6, n.3, p.189-194, 1982.

QUAGGIO, J.A. Métodos de laboratório para calagem em solo. In: RAIJ, B. van; BATAGLIA, O.C.; SILVA, N.M. Coords. Acidez e calagem no Brasil. In: REUNIÃO BRASILEIRA DE FERTILIDADE DO SOLO, 15., Campinas, 1983. Anais...Campinas, Sociedade Brasileira de Ciência do Solo, 1983. p.33-48

RAIJ, B. V.; CANTARELA, H.; QUAGGIO, J.A.; FURLANI, A.M.C. Recomendações de adubação e calagem para o Estado de São Paulo. 2 ed. Campinas: Instituto Agronômico, 1996. 285p. (Boletim Técnico 100).

RAMJEET YADAV, L. K. et al. Effect of Gypsum on Growth and Yield of Groundnut (Arachis hypogaea L.). Environment \& Ecology, v.33, n.2, p. 676-679, April-June, 2015.

RODRIGUES FILHO, F.S.Q.; GODOY, I.J.; FERTISA, C.T. Acúmulo de matéria seca e nutrientes em plantas de amendoim cultivar Tatu-76. Revista Brasileira de Ciência Solo, v.10, p.61-66, 1986.

SANTOS, R.C.S. O Agronegócio do Amendoim no Brasil. Embrapa Algodão. Campina Grande- PB. 2005. 451p.

SEGATO, S.V.; PENARIOL, A.L. A cultura do amendoim em áreas de reforma de canavial In: SEGATO, S.V. et al. (Org.). Expansão e renovação de canavial. p. 85-116. 2007.

SICHMANN, W.; NEPTUNE, A.M.L.; MELLO, F.A.F. de. Efeito da aplicação de calcário e gesso na produção de vagens e sobre algumas características dos frutos de amendoim (Arachis hypogaea L.) em experimento conduzido em vasos contendo um podzólico de Lins e Marília. Anais...Escola Superior Agronomia “Luis de Queiroz”, v.39, p. 337-347, 1982.

SILVA, F. de A. S. e; AZEVEDO, C. A. V. de. The Assistat Software Version 7.7 and its use in the analysis of experimental data. Afr. J. Agric. Res, v.11, n.39, p.3733-3740, 2016. 
SPINOLA, M. C.; CICERO, S. M. Qualidades físicas e fisiológicas de amendoim submetidas a doses de gesso agrícola combinados a épocas e modos de aplicação: II. Área sem calagem.

Revista Brasileira de Sementes, v. 24, n. 1, p.229-236, 2002.

TASSO JUNIOR, L.C.; MARQUES, M.O.; NOGUEIRA, G.DE. A. A cultura do amendoim. Jaboticabal: 2004. 220p.

VITTI, G.C.; FERREIRA, M.E.; MALAVOLTA, E. O gesso agrícola como fonte de cálcio e enxofre - respostas de culturas anuais e perenes. In: SEMINÁRIO SOBRE O USO DO FOSFOGESSO NA AGRICULTURA, Brasília, 1985. Anais... Brasília: EMBRAPA DDT, 1986. p.17-43.

VITTI, G. C. et al. Uso do gesso em sistemas de produção agrícola. Piracicaba: GAPE, 2008. $104 p$.

WALKER, M.E. Calcium requirements for peanut. Soil Science Plant Analysis, v.6, n.3, p.229$313,1975$.

WALKER, M.E.; MULLINIX JUNIOR, B.G.; KEISLING, T.C. Calcium level in the peanut fruiting zone as influenced by gypsum partite size and application rate and time.

Communications in Soil Science and Plant Analysis, New York, v.12, p.427-439, 1981.

WILLIAMS, E.J.; DREXLER, J.S. A non-destructive method for determining peanut pod maturity. Peanut Science, Raleigh, v.8, n.2, p.134-141. 1981.

YORK JUNIOR, E.T.; COLWELL, W.E. Soil properties, fertilization and maintenance of soil fertility. In: SYMPOSIUM OF THE PEANUT, THE UNPREDICTABLE LEGUME, 1951, Washington. Proceedings... Washington: National Fertilizers Association, 1951. p.122-171. 